\title{
Are covert verbal responses mediating false implicit memory?
}

\author{
MARTIN LÖVDÉN \\ Stockholm University, Stockholm, Sweden
}

and

MIKAEL JOHANSSON

Lund University, Lund, Sweden

\begin{abstract}
In the DRM paradigm, illusory memories of a nonpresented word can be induced by the presentation of strong associates to this word. In two experiments, we explored previous findings of false implicit memory of the nonpresented words (McDermott, 1997; McKone \& Murphy, 2000). Experiment 1 extended the finding of false priming to the anagram task. Furthermore, participants attributed this "false" influence on performance to the difficulty of the anagrams and judged them as easier to solve for other students. In Experiment 2, articulatory suppression during the study of the associates resulted in nonsignificant levels of false priming, whereas the normal priming effect was in the same range as that observed in Experiment 1. The study replicates and extends findings of false implicit memory to the anagram task and suggests that future studies should examine the role of covert verbal responses in producing false implicit memory.
\end{abstract}

False memories can be induced reliably by the presentation of words that are strong associates of a nonpresented critical word (Deese, 1959; Roediger \& McDermott, 1995). For example, for the critical word sleep, the presented list of words may consist of bed, rest, awake, and tired. The false memories created by the Deese/RoedigerMcDermott (DRM) paradigm are often accompanied by high confidence ratings (Roediger \& McDermott, 1995), and they occur under conditions of explicit warnings (e.g., McDermott \& Roediger, 1998). The participants also tend to remember particular details of the encoding event and to classify the recollective experience of false memories as a remembering experience (e.g., Roediger $\&$ McDermott, 1995).

The precise cognitive mechanisms behind this associative memory illusion are considerably debated, but the most widely endorsed theories either apply the fuzzy trace theory (e.g., Reyna \& Brainerd, 1995) or embrace some version of an activation-monitoring account (see Roediger, McDermott, \& Robinson, 1998, for a review). In the activation-monitoring accounts, the activation of a critical item at encoding is a result of automatic semantic spreading activation (e.g., Roediger, Balota, \& Watson, 2001). In turn, this could spark an associative response of an image of the critical word (McKone \& Murphy, 2000)

Thanks to Lars-Göran Nilsson and the memory group at Stockholm University for comments on an earlier draft of this article. Correspondence concerning this article should be addressed to M. Lövdén, School of Psychology, Saarland University, Im Stadtwald, Building 1, D-66123 Saarbrücken, Germany (e-mail: m.loevden@mx.uni-saarland.de). or elicit covert verbal responses (CVRs) that are phonologically and consciously activated, as in inner speech and mental rehearsal (McDermott, 1997; Underwood, 1965). False remembering may later occur due to a failure to monitor the source of this activation. For example, false memories may arise from a breakdown in reality monitoring of the type "did I hear the word being presented or did I only think of it?" (Johnson \& Raye, 1981). Similarly, the fluency with which the critical item is processed might by misattributed to an experience of remembering, as proposed by the attributional memory framework (e.g., Jacoby, Kelley, \& Dywan, 1989).

Although we do not want to imply that retrieval factors are of less importance for the creation of false memories in the DRM paradigm, activation factors are the focus of the present study. The utilization of indirect tests is particularly suitable for the study of activation processes involved in the DRM paradigm. Since many of the strategicmonitoring and decision processes involved in explicit retrieval may be excluded, the activation factors become isolated from factors that otherwise would have clouded the interpretation of results. Previously acquired knowledge of perceptual implicit memory tests adds to the rationale that makes indirect testing useful. For example, activation of a concept at a semantic level, in the absence of lexical activation, yields no long-term priming on perceptual tests (e.g., Durgunoğlu \& Roediger, 1987). However, when a word is lexically activated, priming is generally about half as great as priming for presented words (Kirsner, Dunn, \& Standen, 1989). Thus, if the critical words in the DRM paradigm are lexically activated by an associative response, a false priming effect, albeit some- 
what smaller than that found for presented words, would be expected. Equipped with this line of reasoning, McDermott (1997) examined false priming in two perceptual indirect tests (word stem completion and fragment completion) that were administered after a visual presentation of the DRM lists. She obtained reliable false priming effects in the fragment completion test and a trend toward priming in the stem completion test. Furthermore, a robust false priming effect of approximately half the magnitude of the priming effect for presented critical words emerged when data from both tests were combined. McDermott concluded that the critical words might be consciously activated during study as CVRs, and might not be activated only by automatic semantic spreading activation.

However, there are several critical assumptions in the line of reasoning outlined above. Most important, the assumption that perceptual tests are "implicitly" and perceptually process pure may not stand on solid ground. However, McKone and Murphy (2000) set out to replicate the findings of false implicit memory in the stem completion test and obtained false priming of approximately the same magnitude as the normal priming effect. Furthermore, changing modality from visual to auditory presentation of the associates reduced false priming to nonsignificant levels on a written test. One explanation put forward by McKone and Murphy to account for this modality specificity was that the associative response is tied to the presentation modality used at study. That is, they suggested that visually presented lists lead to imagery of the critical word and lexical access in its orthographic form, whereas auditory presentation results in covert labeling of the critical word and lexical access in its phonological form. Thus, in this account, activation in the modality corresponding to the test modality is necessary to achieve priming.

The background outlined above suggests that semantic spreading activation is the basic mechanism underlying activation in the DRM paradigm. In turn, this mechanism might elicit either a phonological representation of the critical word (i.e., a CVR) or an image of the critical word (i.e., orthographic activation), perhaps depending on the characteristics of the study episode.

To complicate the pattern, however, Zeelenberg and Pecher (2002) failed to extend the finding of false implicit memory to lexical decision. They suggested that previous findings of false implicit memory might suffer from explicit contamination and concluded that their results were consistent with the transfer-appropriate processing view (e.g., Morris, Bransford, \& Franks, 1977), that activation of perceptual and orthographic codes is necessary for priming to occur in a written test, and that no such activation of the critical words occurs in the DRM paradigm.

\section{EXPERIMENT 1}

In the first experiment, we adopted a version of the anagram test (Kelley \& Jacoby, 1996) to extend the finding of false priming to another perceptual indirect test. In this version of the anagram test, the participants are required to solve each anagram and to rate how difficult it would be for other participants to solve each anagram. The findings from Kelley and Jacoby's (1996) study were consistent with the notion that the participants used the fluency with which they solved each anagram as a basis for judging difficulty. Specifically, prior presentation of the solution words primed both the latency for solving the anagrams and the difficulty ratings. In addition, the individual latency rating correlations were high. A finding of false priming in the difficulty ratings would be particularly interesting, since this would imply that false implicit memory might serve as a basis for judgments that may have consequences for other people.

\section{Method}

\section{Participants}

Fifty-four undergraduate psychology students (35 women and 19 men; mean age $=26.8$ years) participated in the experiment for course credit. Swedish had been the primary language of all the participants for at least 10 years. They were tested individually.

\section{Design and Materials}

Twenty-four 12-item lists of associates were constructed from the Swedish version of the DRM lists (Johansson \& Stenberg, 2002). The 24 lists that produced the highest false recognition rates were chosen as materials, on the condition that the word frequency of the critical word was lower than 90 per million (Språkbanken, 1998) and that a unique solution to the corresponding anagram was obtained. The 12 items with the strongest forward associative strength (i.e., from critical items to associates) were chosen from the original lists. The number of letters in each critical word varied between three and eight. All the anagrams used during testing were constructed by moving one randomly selected letter to another position in the word (e.g., doctor-octodr).

The design used in both the experiments reported in this paper was adopted from McDermott (1997). The 24 lists were divided into three sets, which were approximately equal in respect to word frequency of the critical item, the probability of producing false recognition, and the difficulty of solving the anagram. The latter measure originated from a pilot experiment of 15 participants. The three sets corresponded to three conditions. In the presented condition, the critical item always replaced the fourth word on each list. Thus, the critical item was actually presented to the participant in the study phase. In the critical condition, the critical item was not presented, although the corresponding associates were. This represented the condition in which false priming could occur. In the baseline condition, the lists were not presented for study at all. The sets used in each condition were counterbalanced according to a Latin square, and the order of presentation at study of the presented and the critical conditions was counterbalance d in an ABBABAAB fashion.

All the items were presented in lowercase letters centered on the screen of a Macintosh PowerBook G3. All the letters were typed using the Arial font and were approximately $6 \mathrm{~mm}$ high and $3 \mathrm{~mm}$ wide. The participant looked at the screen from a distance of approximately $50 \mathrm{~cm}$.

\section{Procedure}

Study phase. The 16 lists were presented on the computer screen under instructions to remember the words for a later memory test. The words appeared for $3 \mathrm{sec}$ each, with an interstimulus interval of $500 \mathrm{msec}$. Each list was always presented in a descending order of associative strength, and there was 15 -sec break between the lists. 
Test phase. The participants were instructed to solve anagrams and were told that they would have a maximum of $20 \mathrm{sec}$ to solve each one. When they had reached a solution, they were to press the mouse button and say the solution word aloud. They were explicitly encouraged not to guess and to be sure that they provided a correct answer. Incorrect answers were rare, as were failures to solve the anagram within the specified time limit. After solving the anagram, it reappeared with a rating scale below. The participants were instructed to rate how difficult the anagram would seem to other students and to give their estimate with a mouse click on a line labeled "very easy" on the left and "very hard" on the right (range, 1-285). The participant started the next trial when ready.

After 12 practice trials consisting of only unrelated anagrams, one randomly ordered list of 56 anagrams was presented for testing. These corresponded to the eight presented critical words (presented), the eight critical nonpresented words (critical), and the eight critical words from the lists not studied at all (baseline). In addition, 16 standard associates from the presented lists, 8 unrelated standard associates from the lists not studied, and 8 totally unrelated filler items were included. The presented standard words were taken from list positions other than 1,4 , and 12 . The session lasted for approximately $40 \mathrm{~min}$ in total.

Debriefing. Only 2 participants reported a strategy for solving the anagrams that included deliberate recall of the words from the study phase (a reported strategy associated with very poor performance). These 2 participants were replaced.

\section{Results and Discussion}

The results from Experiment 1 are summarized in the top of Table 1. The statistical analyses, with an alpha level set at .05 in all analyses, revealed a significant priming effect (i.e., experimental condition vs. baseline) in terms of latency for the presented condition $[M=1,074 \mathrm{msec}$; $t(53)=3.18, S E M=338]$. This result was reflected in the difficulty ratings $[M=15.6 ; t(53)=4.10, S E M=3.8]$. Priming in the critical condition was reliable for the latency measure $[M=702 \mathrm{msec} ; t(53)=2.04, S E M=344]$ and for the difficulty ratings $[M=8.0 ; t(53)=2.12$, $S E M=3.8]$. The difference between the condition involving presented items and the critical condition was not significant, either in terms of latency $[t(53)=1.33]$ or in terms of difficulty ratings $[t(53)=1.78]$. The priming effect for the associates of the critical words was signifi-

Table 1

Difficulty Ratings and Reaction Times (RTs) for Solving Anagrams

\begin{tabular}{|c|c|c|c|c|c|}
\hline \multirow[b]{2}{*}{ Item Status } & \multirow{2}{*}{$\begin{array}{c}\text { Study } \\
\text { Condition }\end{array}$} & \multicolumn{2}{|c|}{$\mathrm{RT}$} & \multicolumn{2}{|c|}{ Difficulty } \\
\hline & & $M$ & SEM & $M$ & SEM \\
\hline \multicolumn{6}{|c|}{ Experiment 1} \\
\hline \multirow[t]{3}{*}{ Critical } & presented & 2,929 & 233 & 58.1 & 4.6 \\
\hline & critical & 3,301 & 240 & 65.8 & 5.0 \\
\hline & baseline & 4,003 & 277 & 73.8 & 5.0 \\
\hline \multirow[t]{2}{*}{ Associates } & presented & 3,802 & 228 & 64.9 & 4.8 \\
\hline & baseline & 4,639 & 238 & 71.6 & 4.7 \\
\hline \multicolumn{6}{|c|}{ Experiment 2} \\
\hline \multirow[t]{3}{*}{ Critical } & presented & 3,395 & 259 & 65.2 & 4.8 \\
\hline & critical & 4,268 & 340 & 73.2 & 5.7 \\
\hline & baseline & 4,377 & 274 & 76.5 & 4.9 \\
\hline \multirow[t]{2}{*}{ Associates } & presented & 4,173 & 257 & 69.8 & 4.9 \\
\hline & baseline & 4,941 & 276 & 72.6 & 4.8 \\
\hline
\end{tabular}

$\overline{\text { Note-CRTs are in milliseconds. Difficulty was judged on a 285-point }}$ scale, from very easy to very difficult. cant in terms of latency $[M=837 \mathrm{msec} ; t(53)=2.95$, $S E M=284]$ and was borderline significant in terms of difficulty ratings $[M=6.6 ; t(53)=1.92, S E M=3.5, p=$ $.06]$. The averaged latency ratings correlation was .40 in the presented condition and .48 in the critical condition.

The findings from Experiment 1 replicate and extend previous results of false priming effects in perceptual indirect tests (McDermott, 1997; McKone \& Murphy, 2000). The fact that we used a different indirect task than had prior studies provides converging evidence for the generality of false implicit memory. These results also argue in favor of the activation of an associative response of the critical item during encoding. Specifically, semantic activation in isolation from some perceptual or lexical activation should not cause long-term priming effects in a perceptual indirect test (e.g., Durgunoğlu \& Roediger, 1987). The factors responsible for the false priming effect may involve CVRs for the critical words (McDermott, 1997; Underwood, 1965) or orthographic activation in a visual perceptual system (McKone \& Murphy, 2000).

\section{EXPERIMENT 2}

We introduced an articulatory suppression task, requiring the participants to utter a repeated irrelevant sound (Coca-Cola) during study. Using this manipulation, Berry, Banbury, and Henry (1997) found reduced levels of cross-modal priming (visual-study-auditorytest), but intact within-modality priming (visual-studywritten-test). The conclusion was that participants generated phonological codes during visual study, which might have been responsible for the cross-modal priming. In line with their results, we expected that priming for the presented items would be intact under articulatory suppression. In addition, articulatory suppression should not impair visuospatial rehearsal (e.g., Farmer, Berman, \& Fletcher, 1986). Hence, if orthographic activation in a visual system was responsible for the false priming effect observed in Experiment 1, we would expect the effect to remain. However, if CVRs contribute to false implicit memory, suppression would interfere with these verbal responses, and the false priming effect would be reduced.

\section{Method}

\section{Participants}

Fifty-four undergraduate psychology students (41 women and 13 men; mean age $=28.0$ years) participated in the experiment for course credit. Swedish had been the primary language for all the participants for at least 10 years. Two participants were replaced after they reported trying to use deliberate recall to solve the anagrams.

\section{Design, Materials, and Procedure}

The design, materials, and experimental setting were the same as those in Experiment 1. However, the participants were instructed to continually say the word "Coca-Cola" aloud during the study phase, at a rate of roughly two "Coca-Colas" per word presented.

\section{Results and Discussion}

The results are summarized in the lower half of Table 1, and the priming effects (latency) from Experiments 1 
and 2 are depicted in Figure 1. The statistics confirmed the priming effect in the presented condition, as reflected in the latency measure $[M=981 \mathrm{msec} ; t(53)=3.05$, $S E M=321]$ and the difficulty ratings $[M=11.3 ; t(53)=$ $2.57, S E M=4.4]$. However, priming in the critical condition was not significant $[t(53)<1$ for both the latency and the rating measures]. The difference between the presented and the critical conditions was significant in terms of latency $[M=873 \mathrm{msec} ; t(53)=2.59, S E M=$ $337]$ and was borderline significant in terms of ratings $[M=8.0 ; t(53)=1.96, S E M=4.1, p=.056]$. Priming for the associates to the critical words was reliable for the latency measure $[M=768 \mathrm{msec} ; t(53)=3.16, S E M=$ 243 ] but was not significant in terms of difficulty ratings $[t(53)<1]$. The averaged latency rating correlations were .45 for the presented condition and .51 for the critical condition.

\section{GENERAL DISCUSSION}

In both experiments, the correlation between speed of solving anagrams and rated difficulty was high enough to be consistent with the notion that the participants used their subjective experience of anagram difficulty as a basis for judging the level of difficulty for others. Kelley and Jacoby (1996) argued that the participants in their experiments failed to realize that their subjective experience of difficulty could be ruined as a judgment criterion for others, because specific past experiences may affect one's current performance. In the present experiments, this effect of specific past experiences is indexed by the priming effect for presented items. A number of previous studies have demonstrated such misattributions of fluency for previously presented items. For example, misattributions of fluent processing can make repeated nonfamous names seem famous (Jacoby, Woloshyn, \& Kelley, 1989) and can give rise to an illusion of truth for repeated statements (Begg, Anas, \& Farinacci, 1992). The finding of the present study extends this line of research and reveals an analogous effect for words that were not previously presented. Thus, subjective experience may be spoiled by "false" influences of the past, as indexed by the false priming effect for the difficulty judgments observed in Experiment 1.

Experiment 1 also replicates and extends the finding of long-term false implicit memory (McDermott, 1997; McKone \& Murphy, 2000) to the anagram test, and the results from Experiments 1 and 2, taken together, suggest a dissociation between false and veridical memory caused by articulatory suppression, which primarily may affect false implicit memory. Specifically, the priming effect for the presented critical items in Experiment 2 was in the same range as that in Experiment 1, but the priming effect in the critical condition was small, as compared with Experiment 1. The finding of nonsignificant levels of false priming following suppression is consistent with the notion that CVRs, sparked by semantic spreading activation, contributed to the activation factors responsible for the observed false priming effect. That is, articulatory suppression should not impair visuospatial rehearsal (Farmer et al., 1986), which, according to the modality-specific explanation (McKone \& Murphy, 2000), is responsible for the false priming effect in visual indirect tests. To recapitulate, McKone and Murphy found that changing modality from visual to auditory presentation of the associates reduced false priming on a written test. One of the suggested accounts of this modality specificity was that the associative response could be tied to the presentation modality used at study. In other words, visually presented lists are sug-

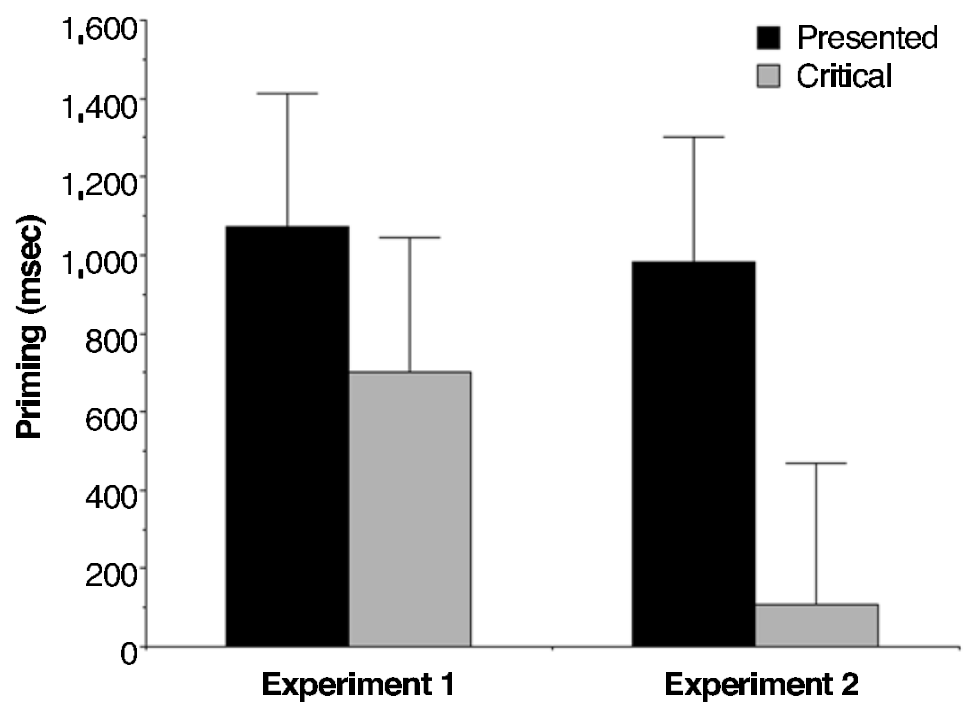

Figure 1. Mean (with $S E M$ ) priming in milliseconds as a function of experiment and condition. 
gested to lead to imagery of the critical word, whereas auditory presentation results in covert labeling of the critical word. Although the data do not directly address the modality effects observed by McKone and Murphy, one might note that this effect is not necessarily inconsistent with the present study. Specifically, there is no reason to expect that visual presentation leads to associative responses in the orthographic form, whereas auditory presentation leads to CVRs. In fact, one could argue that activation of the critical word in a phonological store should be the preferred mode when the associates are visually presented, since the visual system would be occupied with the presented information. Conversely, imagery of the critical words might be the preferred mode under auditory presentation of the associates. One might speculate that auditory presentation might reduce false priming on a written test because it, in fact, would lead to imagery, but of abstract representations of the critical words, rather than of the orthographic form, which perhaps do not lead to priming. Clearly, the intriguing modality effect observed by McKone and Murphy deserves further exploration.

There is evidence suggesting that anagram solving (e.g., Fink \& Weisberg, 1981) and priming in the word stem completion task (Rueckl \& Mathew, 1999) involve a phonological component, in addition to components based on orthographic information. With this evidence in the picture, one possible account of the mechanisms underlying priming in the present data is that "true" priming is primarily mediated by orthographic information, whereas "false" priming is mediated by phonological information. Speculatively, the findings of no false implicit memory in lexical decision (Zeelenberg \& Pecher, 2002) could merely reflect the possibility that different indirect tests may tap phonological and orthographic representations to different degrees. In other words, it is conceivable that anagram solving and word stem completion might include phonological task components to a greater degree than does lexical decision. Hence, as the transfer-appropriate processing account suggests, an associative response during study may result in false implicit memory only when the indirect test taps the corresponding encoding process.

However, it is conceivable that the suppression task had a more global capacity-delimiting effect, possibly also affecting imagery, rather than only impairing CVRs. In this vein, previous research has shown that perceptual indirect tests are generally unaffected by manipulations of divided attention at the study phase (e.g., Mulligan, 1998). Hence, the fact that priming in the presented condition was also robust following articulatory suppression may be taken as evidence for the perceptual nature of the anagram task. If this is the case, the priming for critical words obtained in Experiment 1 cannot be attributed to conceptual and explicit factors alone (see Zeelenberg \& Pecher, 2002) but must include the notion of some lexical activation of the critical word-stemming either from a CVR or from imaging of the critical word in its ortho- graphic form. It should also be noted that the extensive debriefing performed enabled us to replace those participants reporting use of explicit retrieval strategies to solve the anagrams. Furthermore, these few participants had a dramatically impaired overall performance-an observation suggesting that explicit retrieval strategies might have been maladaptive and, therefore, not likely to have been adopted.

We think that several results converge to confirm the hypothesis that phonological coding of associative responses, in the absence of data-driven perceptual activation, may lead to priming on perceptual indirect tests. For example, auditory presentation (e.g., Rajaram \& Roediger, 1993) and generating a word from a conceptual cue (e.g., hot-c___ leads to priming in written tests (e.g., Jacoby, 1983). Hence, data-driven activation in the perceptual representation system corresponding to the test modality may not be needed to achieve priming. Taking these findings together with the present data, we suggest that a plausible account is that CVRs are at least one of the factors behind false implicit memory.

A consistent finding in both of the experiments reported here was that priming for the associates was somewhat less pronounced than priming for the presented critical items. This finding is inconsistent with the results from McDermott's (1997) study, and we currently have no explanation for this pattern of findings. However, the present finding might illuminate some inconsistencies between the results from McDermott's study and those from McKone and Murphy's (2000) study. Whereas McDermott's study and the present results reveal false priming at a level of approximately half the "true" priming effect, McKone and Murphy found equivalent levels of priming. However, McKone and Murphy used a design that permitted comparison only of critical words with associates, rather than between presented critical and nonpresented critical items. Under the present circumstances, the conclusion that "false" priming effects are as large as the "true" priming effects might occur if comparisons are made between false priming and the weaker effect for associates, rather than with the priming effect stemming from presented critical items.

In conclusion, the present study reveals misattributions stemming from "false" fluency and false implicit priming in the anagram test that is diminished following articulatory suppression. Future studies should further examine the role of CVRs as an activation factor in the DRM paradigm and in producing false implicit memory.

\section{REFERENCES}

Begg, I. M., Anas, A., \& Farinacci, S. (1992). Dissociation of processes in belief: Source recollection, statement familiarity, and the illusion of truth. Journal of Experimental Psychology: General, 121, 446-458.

Berry, D. C., Banbury, S., \& Henry, L. (1997). Transfer across form and modality in implicit and explicit memory. Quarterly Journal of Experimental Psychology, 50A, 1-24.

DEESE, J. (1959). On the prediction of occurrence of particular verbal 
intrusions in immediate recall. Journal of Experimental Psychology, 58, $17-22$.

DurgunoĞlu, A. Y., \& Roediger, H. L., III (1987). Test differences in accessing bilingual memory. Journal of Memory \& Language, 26, 377-391.

Farmer, E. W., Berman, J. V. F., \& Fletcher, Y. L. (1986). Evidence for a visuo-spatial scratch-pad in working memory. Quarterly Journal of Experimental Psychology, 38A, 675-688.

Fink, T. E., \& WeIsberg, R. W. (1981). The use of phonemic information to solve anagrams. Memory \& Cognition, 9, 402-410.

JACOBY, L. L. (1983). Remembering the data: Analyzing interactive processes in reading. Journal of Verbal Learning \& Verbal Behavior, 22, 485-508.

JAcoby, L. L., Kelley, C. M., \& Dywan, J. (1989). Memory attributions. In H. L. Roediger III \& F. I. M. Craik (Eds.), Varieties of memory and consciousness: Essays in honour of Endel Tulving (pp. 391422). Hillsdale, NJ: Erlbaum.

JACoBy, L. L., Woloshyn, V., \& Kelley, C. (1989). Becoming famous without being recognized: Unconscious influences of memory produced by dividing attention. Journal of Experimental Psychology: General, 118, 115-125.

Johansson, M., \& Stenberg, G. (2002). Inducing and reducing false memories: A Swedish version of the Deese-Roediger-McDermott paradigm. Scandinavian Journal of Psychology, 43, 369-383.

Johnson, M. K., \& RaYe, C. L. (1981). Reality monitoring. Psychological Review, 88, 67-85.

Kelley, C. M., \& JACOBy, L. L. (1996). Adult egocentrism: Subjective experience versus analytic bases for judgment. Journal of Memory \& Language, 35, 157-175.

Kirsner, K., Dunn, J. C., \& Standen, P. (1989). Domain-specific resources in word recognition. In S. Lewandowsky, J. C. Dunn, \& K. Kirsner (Eds.), Implicit memory: Theoretical issues (pp. 99-122). Hillsdale, NJ: Erlbaum.

McDermott, K. B. (1997). Priming on perceptual implicit memory tests can be achieved through presentation of associates. Psychonomic Bulletin \& Review, 4, 582-586.

McDermott, K. B., \& Roediger, H. L., III (1998). Attempting to avoid illusory memories: Robust false recognition of associates persists under conditions of explicit warnings and immediate testing. Journal of Memory \& Language, 39, 508-520.
McKone, E., \& Murphy, B. (2000). Implicit false memory: Effects of modality and multiple study presentations on long-lived semantic priming. Journal of Memory \& Language, 43, 89-109.

Morris, C. D., Bransford, J. D., \& Franks, J. J. (1977). Levels of processing versus transfer appropriate processing. Journal of Verbal Learning \& Verbal Behavior, 16, 519-533.

Mulligan, N. W. (1998). The role of attention during encoding in implicit and explicit memory. Journal of Experimental Psychology: Learning, Memory, \& Cognition, 24, 27-47.

Rajaram, S., \& RoEDiger, H. L., III (1993). Direct comparison of four implicit memory tests. Journal of Experimental Psychology: Learning, Memory, \& Cognition, 19, 765-776.

Reyna, V. F., \& Brainerd, C. J. (1995). Fuzzy trace theory: An interim synthesis. Learning \& Individual Differences, 7, 1-75.

Roediger, H. L., III, Balota, D. A., \& Watson, J. M. (2001). Spreading activation and arousal of false memories. In H. L. Roediger III, J. S. Nairne, I. Neath, \& A. M. Surprenant (Eds.), The nature of remembering: Essays in honor of Robert G. Crowder (pp. 95-115). Washington, DC: American Psychological Association.

Roediger, H. L., III, \& McDermott, K. B. (1995). Creating false memories: Remembering words not presented in lists. Journal of Experimental Psychology: Learning, Memory, \& Cognition, 21, 803-814.

Roediger, H. L., III, McDermott, K. B., \& Robinson, K. J. (1998). The role of associative processes in creating false memories. In M. A. Conway, S. E. Gathercole, \& C. Cornoldi(Eds.), Theories of memory II (pp. 187-245). Hove, U.K.: Psychological Press.

Rueckl, J. G., \& MATHEW, S. (1999). Implicit memory for phonological processes in visual stem completion. Memory \& Cognition, 27, $1-11$.

SPRÅKBANKEN (1998). Språkbankens konkordanser: Press 97 [Electronic database]. Göteborg: Göteborgs Universitet, Institutionen för svenska språket. Available from http://spraakbanken.gu.se.

UNDERWOOD, B. J. (1965). False recognition produced by implicit verbal responses. Journal of Experimental Psychology, 70, 122-129.

Zeelenberg, R, \& Pecher, D. (2002). False memories and lexical decision: Even twelve primes do not cause long-term semantic priming. Acta Psychologica, 109, 269-284.

(Manuscript received January 31, 2002; revision accepted for publication June 12, 2002.) 